\title{
How many individuals with asthma need to be vaccinated to prevent one case of invasive pneumococcal disease?
}

\author{
Julie M Okapuu MDCM FRCPC ${ }^{1}$, Estelle Chétrit MDCM MBA2, \\ Brigitte Lefebvre $\mathrm{PhD}^{3,4}$, Caroline Quach MD MSc FRCPC ${ }^{1,2,4,5}$
}

\begin{abstract}
JM Okapuu, E Chétrit, B Lefebvre, C Quach. How many individuals with asthma need to be vaccinated to prevent one case of invasive pneumococcal disease? Can J Infect Dis Med Microbiol 2014;25(3):147-150.
\end{abstract}

BACKGROUND: The American Advisory Committee on Immunization Practices recommended the inclusion of adults with asthma in the high-risk category for pneumococcal vaccination based on a twofold increase in risk of invasive pneumococcal disease (IPD). OBJECTIVE: To determine whether, among individuals with asthma, the number needed to vaccinate (NNV) using pneumococcal conjugate vaccine (PCV)-13 or 23-valent pneumococcal polysaccharide vaccine (PPV-23) warrants its addition to the high-risk category for pneumococcal vaccination in Canada.

METHODS: Using IPD incidence (per 10,000 individuals) figures from published articles (4.2 in high-risk asthmatics, 2.3 in low-risk asthmatics and 1.2 in healthy individuals), the NNV to prevent one case of IPD in asthmatics five to 17 years of age and 18 to 50 years of age was calculated, factoring in the proportion of pneumococcal serotypes included in vaccines (based on data from Quebec) and accounting for the possibility of waning vaccine efficacy (VE) using four scenarios.

RESULTS: Assuming a VE of $65 \%$ for PCV-13 in asthmatics, the NNV would be 704 to 820 in low-risk and 386 to 449 in high-risk children; and 355 to 1532 in low-risk and 195 to 839 in high-risk adults (range depends on waning scenario). Assuming a VE of $65 \%$ for PPV-23 in asthmatics, the NNV would be 581 to 677 in low-risk and 318 to 371 in high-risk children; and 246 to 1059 in low-risk and 135 to 580 in high-risk adults.

CONCLUSION: The NNV with both PCV-13 and PPV-23 in asthmatic children and adults is comparable with that of other high-risk conditions such as age $\geq 65$ years. Therefore, the addition of asthma to the list of highrisk conditions for pneumococcal vaccination is warranted.

Key Words: Asthma; Pneumococcal; Vaccine

\author{
Combien de personnes asthmatiques ont besoin \\ d'être vaccinées pour prévenir un cas de \\ pneumococcie invasive?
}

HISTORIQUE : L'American Advisory Committee on Immunization
Practices a recommandé d'inclure les adultes asthmatiques dans la caté-
gorie à haut risque chez qui recommander la vaccination antipneumo-
coccique, car le risque de pneumococcie invasive (PI) double au sein
de ce groupe. OBJECTIF : Chez les personnes asthmatiques, déterminer si le nombre de sujets à vacciner (NSV) à l'aide du vaccin antipneumococcique conjugué 13-valent (Pneu-C-13) ou polysaccharidique 23-valent (Pneu-P-23) en justifie l'ajout à la catégorie à haut risque chez qui recommander la vaccination antipneumococcique au Canada.

MÉTHODOLOGIE : D'après l'incidence de PI (sur 10000 habitants) tirée d'articles publiés (4,2 chez les asthmatiques à haut risque, 2,3 chez les asthmatiques à faible risque et 1,2 chez les personnes en bonne santé), les chercheurs ont calculé le NSV pour prévenir un cas de PI chez les asthmatiques de cinq à 17 ans et de 18 à 50 ans, compte tenu de la proportion de sérotypes du pneumocoque incluse dans les vaccins (d'après des données du Québec) et de la possibilité d'une diminution de l'efficacité vaccinale (EF) selon quatre scénarios.

RÉSULTATS : Si l'EV du Pneu-C-13 est de $65 \%$ chez les asthmatiques, le NSV se situerait entre 704 et 820 chez les enfants à faible risque, 386 et 449 chez les enfants à haut risque, 355 et 1532 chez les adultes à faible risque et 195 et 839 chez les adultes à haut risque (la plage dépend du scénario de diminution). Si l'EV du Pneu-P-23 est de $65 \%$ chez les asthmatiques, le NSV se situerait entre 581 et 677 chez les enfants à faible risque, 318 et 371 chez les enfants à haut risque, 246 et 1059 chez les adultes à faible risque et 135 et 580 chez les adultes à haut risque. CONCLUSION : Chez les enfants et les adultes asthmatiques, le NSV à l'aide du Pneu-C-13 et du Pneu-P-23 est comparable à celui observé dans d'autres situations à haut risque, telles qu'un âge de 65 ans ou plus. Par conséquent, il est justifié d'ajouter l'asthme à la liste de situations à haut risque pour lesquelles recommander la vaccination antipneumococcique.

residence in a long-term care facility $(1,2)$. Furthermore, homeless individuals and individuals who use illicit drugs may also be at increased risk (3). In Canada, children between two months and 18 years of age who belong to high-risk groups should receive a pneumococcal conjugate vaccine (PCV), followed by the 23 -valent pneumococcal polysaccharide vaccine (PPV-23) if $\geq 2$ years of age. The recommendation for adults in these high-risk groups is a dose of PPV-23 (1).

In early 2012, both Health Canada and the United States Food and Drug Administration approved the use of the 13-valent PCV (PCV-13) pulmonary disease, diabetes mellitus, chronic renal disease, dialysis, cirrhosis); cochlear implants; smoking; alcoholism; age $\geq 65$ years; and
${ }^{1}$ Department of Medical Microbiology and Infectious Diseases; ${ }^{2}$ Department of Pediatrics, The Montreal Children's Hospital, McGill University

Health Centre, Montreal; ${ }^{3}$ Laboratoire de santé publique du Québec, Sainte-Anne-de Bellevue; ${ }^{4}$ Institut national de santé publique du Québec;

${ }^{5}$ Department of Epidemiology, Biostatistics and Occupational Health, McGill University, Montreal, Quebec

Correspondence: Dr Caroline Quach, The Montreal Children's Hospital, C1242-2300 Tupper Street, Montreal, Quebec H3H 1 P3.

Telephone 514-412-4485, fax 514-412-4494, e-mail caroline.quach@mcgill.ca
OPEN ACCESS

This open-access article is distributed under the terms of the Creative Commons Attribution Non-Commercial License (CC BY-NC) (http:// creativecommons.org/licenses/by-nc/4.0/), which permits reuse, distribution and reproduction of the article, provided that the original work is properly cited and the reuse is restricted to noncommercial purposes. For commercial reuse, contact support@pulsus.com 
in adults $\geq 50$ years of age, based on noninferior immunogenicity compared with PPV-23 $(4,5)$. However, there is ongoing debate regarding which vaccine should be used in high-risk adults. PPV-23 has the advantage of covering more serotypes and, thus, should be expected to prevent more disease. However, the immunogenicity of conjugate vaccines may be superior for certain serotypes and for certain high-risk groups (6). Furthermore, there may be a benefit to using PCV-13 in high-risk patients $<65$ years of age who will be candidates for a dose of PPV-23 after 65 years of age because there is a theoretical risk of tolerance when two doses of PPV-23 are administered close in time. Published estimates of vaccine effectiveness (VE) for PPV-23 are believed to exceed $80 \%$ in healthy young adults (1), and range from $40 \%$ to $80 \%$ in adults $\geq 65$ years of age and adults with underlying illnesses (1,7-9). PCV-13 efficacy and effectiveness in adults is currently unknown. Therefore, efficacy is extrapolated from data on PCV-7. In healthy individuals, efficacy for the prevention of IPD caused by vaccine serotypes has been reported to be between $89 \%$ and $97 \%(1,10)$. A recent study evaluating the cost effectiveness of different pneumococcal vaccination strategies among adults $\geq 50$ years of age used various VE estimates for PCV-13, based on experts' opinion (11). The VE of PCV-13 was estimated to be $70 \%$ to $100 \%$ in healthy individuals, $60 \%$ to $95 \%$ for adults $>65$ years of age and $0 \%$ to $80 \%$ for immunocompromised patients. VE estimates for PPV-23 were $80 \%$ to $95 \%$ in healthy adults, $60 \%$ to $90 \%$ in adults $>65$ years of age and $0 \%$ to $26 \%$ in immunocompromised patients. Given their basic assumptions, the authors concluded that the use of PCV-13 as a substitute for PPV-23, keeping the same recommendations regarding whom to vaccinate, was more cost effective. However, the authors assumed that PCV-13 prevents pneumonia, while PPV-23 does not - an assumption that appears to increase the cost effectiveness of PCV-13. Furthermore, strategies that used PCV-13 alone were less effective at preventing IPD than strategies that used PPV-23 alone or after PCV-13. In June 2012, the American Advisory Committee on Immunization Practices (ACIP) voted to recommend a dose of PCV-13, followed by a dose of PPV-23 at least eight weeks later, to adults $\geq 19$ years of age if they were immunocompromised, had functional or anatomical asplenia, cerebrospinal fluid leaks or cochlear implants (12).

The Canadian National Advisory Committee on Immunization recommended that chronic pulmonary disease be an indication for vaccination with PPV-23; however, asthmatic patients were excluded from this recommendation, unless they were treated with high-dose oral corticosteroid therapy (2). This differed from the ACIP recommendations, in which adult asthmatics 19 to 64 years of age were classified in the high-risk category for pneumococcal vaccination with PPV-23 (13). The ACIP decision was based on a study that showed a twofold increase in the risk of IPD in asthmatics (14), with an annual incidence rate of IPD per 10,000 individuals of 1.2, 2.3 and 4.2 for healthy, low-risk and high-risk asthmatic populations, respectively. Another study, from Finland, found that $7.1 \%$ of patients with IPD and $2.1 \%$ of control individuals had asthma, and that the matched OR for IPD was 2.8 for low-risk asthma and 12.3 for high-risk asthma (15). They concluded that $5 \%$ of the disease burden of IPD could be attributable to asthma. Finally, a study from Minnesota (USA) also showed an increased risk of serious pneumococcal disease (IPD, pneumonia or both) in patients with asthma (16). Overall, these studies demonstrate that individuals with asthma are, in fact, at increased risk for IPD.

We aimed to determine whether, in individuals with asthma, the number needed to vaccinate (NNV) using PCV-13 or PPV-23 warrants its addition to the high-risk category for pneumococcal vaccination in Canada. We aimed to compare our calculations with the published NNVs for a group that is already considered to be at high risk for IPD: adults $\geq 65$ years of age. Published NNVs with PPV-23 for this group range from 3333 to $5206(7,8)$.

\section{METHODS}

IPD surveillance system

IPD is a reportable disease in Quebec. Quebec has a laboratory surveillance system that is enhanced and complete for all pneumococcal isolates from sterile body fluids from children $\leq 5$ years of age. Isolates from older children and adults are sent on a voluntary basis through a sentinel laboratory surveillance network ( $\mathrm{n}=21$ hospital laboratories). All IPD isolates are sent to the Quebec Public Health Laboratory for serotyping and antimicrobial susceptibility testing. In 2011, the sentinel network only contributed 328 (24\%) of the 1358 isolates that were part of the surveillance program; most of the pneumococcal isolates from sterile sites were, thus, sent through voluntary participation (17). IPD isolates are categorized according to age groups ( 0 to 11 months, 12 to 23 months, 24 to 35 months, 36 to 59 months, five to 11 years, 12 to 17 years, 18 to 49 years, 50 to 64 years and $\geq 65$ years of age). Serotype data are available for each age group. The study population was children five to 17 years of age and adults 18 to 50 years of age.

\section{Study design}

Because the incidence of IPD among asthmatics in Quebec is unknown, published incidence data for unvaccinated subjects available in the literature were used (14): 4.2 episodes per 10,000 individuals with high-risk asthma, 2.3 episodes per 10,000 individuals with low-risk asthma and 1.2 episode per 10,000 individuals without asthma. In the cited study, high-risk asthma was defined as asthma requiring hospital admission or an emergency department visit, use of a course of corticosteroids as rescue therapy, long-term use of oral corticosteroids ( $\geq 120$ days) or dispensing of $\geq 3$ prescriptions for $\beta$-agonists within the previous year.

The NNV was calculated as the inverse of the absolute risk reduction, which was, in turn, divided by the estimated length of vaccine protection (VP). The absolute risk reduction was calculated as the difference in disease incidence between unvaccinated and vaccinated subjects. The NNV and incidence in vaccinated subjects were derived as follows:

$$
\begin{gathered}
\text { NNV }=1 / \text { VP length } \times \\
(1 / \text { incidence unvaccinated }- \text { incidence vaccinated }])
\end{gathered}
$$

$$
\text { Incidence in vaccinated }=\text { incidence in unvaccinated } \times
$$$$
\text { ( } 1-[\mathrm{VE} \times \% \text { serotype coverage]) }
$$

\section{Variables}

Using surveillance data from 2009 to 2012 from Quebec, the proportion of pneumococcal isolates from invasive infections that were included in the two vaccines was accounted for and used as the percent serotype coverage. A sensitivity analysis was performed, varying the percent serotype coverage for PCV-13 between $45 \%$ and $80 \%$ and, for PPV-23, between $60 \%$ and $95 \%$, based on the known Canadian epidemiology (18).

Based on the literature cited in the introduction, the published estimates of VE are highly variable. For simplicity, the VE in healthy children and adults was estimated to be $80 \%$ for both PCV-13 and PPV-23. However, a sensitivity analysis was performed using a worstcase scenario of $60 \% \mathrm{VE}$ and a best-case scenario of $97 \%$ VE. Because the VE in asthmatics is not known but is assumed to be inferior, the VE in this population was arbitrarily decreased to $65 \%$ for PCV-13 and PPV-23. A sensitivity analysis was performed, varying the VE between $45 \%$ and $80 \%$ in this group.

The possibility of waning VE was accounted for using four scenarios. The first assumed no waning VE. The second scenario assumed a steady VE for five years followed by a decline of $1 \%$ per year thereafter. The third scenario assumed a steady VE for 10 years followed by a decline of $2 \%$ per year thereafter. The fourth scenario assumed a steady VE for five years, then a decline of $2.5 \%$ per year for the next 10 years, a decline of $1.67 \%$ per year for the next 15 years and $1.25 \%$ per year for the next 20 years after vaccination. A static model that did not take into account herd immunity or serotype replacement was used. 
TABLE 1

Percent of invasive pneumococcal disease isolates from 2009 to 2012 in Quebec covered by pneumococcal conjugate vaccine (PCV)-13 and pneumococcal polysaccharide vaccine (PPV)-23 according to age group

\begin{tabular}{lcc}
\hline & PCV-13 & PPV-23 \\
\hline $\begin{array}{l}\text { Children } 5 \text { to } 17 \text { years of age } \\
(n=90)\end{array}$ & 63.3 & 76.7 \\
$\begin{array}{l}\text { Adults } 18 \text { to } 50 \text { years of age } \\
(n=301)\end{array}$ & 58.8 & 85.1 \\
Adults $\geq 65$ years of age $(n=676)$ & 46.6 & 64.5 \\
\hline
\end{tabular}

Data presented as \%

\section{RESULTS}

Serotype data

The proportion of isolates that were vaccine serotypes in Quebec from 2009 to 2012 are presented in Table 1 . PCV-13 serotypes $(1,3,4,5$, $6 \mathrm{~A}, 6 \mathrm{~B}, 7 \mathrm{~F}, 9 \mathrm{~V}, 14,18 \mathrm{C}, 19 \mathrm{~A}, 19 \mathrm{~F}$ and $23 \mathrm{~F}$ ) comprised $63.3 \%$ of the IPD strains in children five to 17 years of age, $58.8 \%$ of the strains in adults 18 to 50 years of age, and $46.6 \%$ of the strains in adults $\geq 65$ years of age. PPV-23 serotypes $(1,2,3,4,5,6 \mathrm{~B}, 7 \mathrm{~F}, 8,9 \mathrm{~N}, 9 \mathrm{~V}, 10 \mathrm{~A}$, 11A, 12F, 14, 15B, 17F, 18C, 19A, 19F, 20, 22F, 23F, 33F) comprised $76.7 \%$ of the IPD strains in children five to 17 years of age, $85.1 \%$ of the strains in adults 18 to 50 years of age and $64.5 \%$ of the strains in adults $\geq 65$ years of age.

\section{NNV}

Depending on the waning scenario used, the NNV using PCV-13 varied from 1097 to 1239 for healthy children five to 17 years of age, 704 to 820 for low-risk and 386 to 449 for high-risk asthmatic children five to 17 years of age (Table 2). For adults, the NNV using PCV-13 was between 554 to 1502 for healthy adults 18 to 50 years of age, 355 to 1532 for low-risk and 195 to 839 for high-risk asthmatic adults 18 to 50 years of age (Table 3 ).

Depending on the waning scenario used, the NNV using PPV-23 varied from 905 to 1023 for healthy children, 581 to 677 for low-risk and 318 to 371 for high-risk asthmatic children (Table 2). For adults, the NNV using PPV-23 was between 383 to 1038 for healthy adults, 246 to 1059 for low-risk and 135 to 580 for high-risk asthmatic adults (Table 3).

Sensitivity analysis

Tables 2 and 3 also present the best- and worst-case scenarios for various age groups, using different waning scenarios for both vaccines. Overall, the NNV for children with low-risk asthma could be as high as 1798 (PCV-13) and 1348 (PPV-23), compared with a worst-case scenario of 984 (PCV-13) and 738 (PPV-23) in children with high-risk asthma. For adults, the NNV for low-risk asthma could be as high as 8783 (PCV-13) or 6588 (PPV-23) for low-risk asthma, or 4810 (PCV13) or 3608 (PPV-23) for high-risk asthma.

\section{DISCUSSION}

Current Canadian vaccination guidelines do not include asthma as a high-risk condition warranting pneumococcal vaccination. However, based on our calculations, not taking into account herd immunity and previous vaccination with PCV, the NNV to prevent one case of IPD is low. In fact, the NNV to prevent one case of IPD with both PCV-13 and PPV-23 is lower than in the high-risk groups that are routinely vaccinated. For example, the NNV with PPV-23 in adults $\geq 65$ years of age has been calculated at 3333 in one study (7) and 5206 in another (8).

High-risk groups in Canada are currently vaccinated with PPV-23, although the calculated NNV to prevent one case of IPD with PPV23 and PCV-13 appear to be similar. Due to the immunogenicity advantage of conjugate vaccines and because of its expanded serotype coverage compared with PCV-7, PCV-13 should be further explored as an alternative to PPV-23 in high-risk groups, particularly in immunocompromised populations. However, although there may be
TABLE 2

Number needed to vaccinate and range (best case, worst case) for pneumococcal conjugate vaccine-13 and pneumococcal polysaccharide vaccine-23 in children five to 17 years of age according to the waning scenario

\begin{tabular}{|c|c|c|c|}
\hline \multirow[b]{2}{*}{ Scenario } & \multicolumn{3}{|c|}{ Group } \\
\hline & Healthy & Low-risk asthma & High-risk asthma \\
\hline \multicolumn{4}{|c|}{ Pneumococcal conjugate vaccine-13 } \\
\hline 1 & $1097(716,2058)$ & $704(453,1431)$ & $386(248,784)$ \\
\hline 2 & $1150(744,2192)$ & $747(475,1558)$ & $409(260,853)$ \\
\hline 3 & $1125(731,2129)$ & $727(465,1498)$ & $398(254,820)$ \\
\hline 4 & $1239(791,2429)$ & $820(512,1798)$ & $449(280,984)$ \\
\hline \multicolumn{4}{|c|}{ Pneumococcal polysaccharide vaccine- 23} \\
\hline 1 & $905(603,1543)$ & $581(381,1074)$ & $318(209,588)$ \\
\hline 2 & $949(627,1644)$ & $616(400,1169)$ & $337(219,640)$ \\
\hline 3 & $929(616,1596)$ & $600(391,1123)$ & $328(214,615)$ \\
\hline 4 & $1023(666,1821)$ & $677(431,1348)$ & $371(236,738)$ \\
\hline
\end{tabular}

Scenario 1: no waning vaccine efficacy (VE); Scenario 2: steady VE $\times 5$ years followed by a decline of $1 \%$ per year thereafter; Scenario 3: steady VE $\times$ 10 years followed by a decline of $2 \%$ per year thereafter; Scenario 4: steady $V E \times 5$ years followed by a decline of $2.5 \%$ per year for the following 10 years, $1.67 \%$ per year for the next 15 years and $1.25 \%$ per year for the next 20 years

TABLE 3

Number needed to vaccinate and range (best case, worst case) with pneumococcal conjugate vaccine-13 and pneumococcal polysaccharide vaccine-23 in adults 18 to 50 years of age according to the waning scenario

\begin{tabular}{lccc}
\hline & \multicolumn{3}{c}{ Group } \\
\cline { 2 - 4 } Scenario & Healthy & Low-risk asthma & High-risk asthma \\
\hline \multicolumn{2}{l}{ Pneumococcal conjugate vaccine-13 } \\
1 & $554(336,965)$ & $355(212,671)$ & $195(116,367)$ \\
2 & $650(382,1201)$ & $434(249,910)$ & $238(136,498)$ \\
3 & $690(401,1310)$ & $470(265,1034)$ & $257(145,566)$ \\
4 & $1502(700,5144)$ & $1532(576,8783)$ & $839(315,4810)$ \\
Pneumococcal polysaccharide vaccine-23 & \\
1 & $383(283,723)$ & $246(179,503)$ & $135(98,276)$ \\
2 & $449(322,901)$ & $300(210,682)$ & $164(115,374)$ \\
3 & $477(338,982)$ & $325(223,776)$ & $178(122,425)$ \\
4 & $1038(590,3858)$ & $1059(485,6588)$ & $580(266,3608)$
\end{tabular}

Scenario 1: no waning vaccine efficacy (VE); Scenario 2: steady VE $\times 5$ years followed by a decline of $1 \%$ per year thereafter; Scenario 3: steady VE $\times$ 10 years followed by a decline of $2 \%$ per year thereafter; Scenario 4 : steady VE $\times 5$ years, followed by a decline of $2.5 \%$ per year for the following 10 years, $1.67 \%$ per year for the next 15 years and $1.25 \%$ per year for the next 20 years

an immunogenicity advantage, correlates of protection and the actual efficacy of PCV-13 in adults is yet to be determined. On the other hand, the introduction of PCV-13 vaccination in children may lead to serotype replacement and herd immunity, which may limit the benefit for adults in the future. For example, with the introduction of routine infant vaccination programs with PCV-7 in Canada in 2002, there has been near eradication of IPD caused by PCV-7-serotype strains in both children and adults (19). A surveillance study from Calgary (Alberta) comparing incidence of IPD from 1998 to 2001 (prevaccine period) with 2007 showed a 94\% decline in the incidence of PCV-7-serotype IPD in children $<2$ years of age. They also found a $92 \%$ decline in PCV-7-serotype IPD among adults 65 to 84 years of age and a $29 \%$ decline in overall IPD (20). This is likely due to reduced nasopharyngeal colonization in infants and young children, which may have reduced transmission to adults.

Similar results were observed in the United States; from 1998-1999 to 2008 , overall rates of IPD decreased by $34 \%$ in individuals 18 to 49 years of age, $14 \%$ in those 50 to 64 years of age and $37 \%$ in those 
$\geq 65$ years of age. The rates of IPD caused by PCV-7 serotypes decreased by $90 \%$ to $93 \%$ (21). The impact of serotype replacement with nonvaccine serotypes is not yet known.

Our study is limited by the fact that the efficacy and effectiveness of PCV-13 is not yet known in the adult population; therefore, numbers are extrapolated from studies of PCV-7 involving children. Moreover, the efficacy of PPV-23 could have been overestimated due to the fact that some children and young adults have previously received one or more pneumococcal conjugate vaccines, which would lessen the added benefit of PPV-23. The waning scenario may be overestimating the PPV-23 VE. However, current Canadian guidelines only recommend one dose of PPV-23 without a booster in individuals who have a chronic condition, but who are not otherwise considered immunocompromised. Furthermore, the potential for serotype replacement with the introduction of vaccination in asthmatics was not taken into account, nor was the possibility of herd immunity.

\section{CONCLUSIONS}

The NNV with both PCV-13 and PPV-23 in asthmatic children and adults is comparable with, if not lower than, the NNV to prevent one case of IPD in individuals with high-risk conditions such as age $\geq 65$ years. Therefore, asthma should be added to the list of high-risk conditions warranting pneumococcal vaccination in Canada. Further analyses are needed to evaluate the cost effectiveness of vaccination in this risk group. Given the similar calculated $\mathrm{NNV}_{\mathrm{s}}$, the limited data on PCV-13, and the lower cost of PPV-23, the best strategy pending further studies would be to vaccinate adult asthmatics in Canada with PPV-23.

\section{REFERENCES}

1. Pneumococcal vaccine. In: National Advisory Committee on Immunization. Canadian Immunization Guide, 7th edn. Ottawa: Public Health Agency of Canada, 2006.

2. National Advisory Committee on Immunization. Recommendations for use of pneumococcal 23-valent polysaccharide vaccine during shortage. Canadian Communicable Disease Report 2004;30(ACS-4).

3. National Advisory Committee on Immunization. Statement on the recommended use of pneumococcal 23 -valent polysaccharide vaccine in homeless persons and injection drug users. CCDR 2008;34(ACS-5).

4. Health Canada approves extended use of Prevnar ${ }^{\circledR} 13$ in adults 50 years and older. <www.pfizer.ca/en/media_centre/news_releases/ article? year $=2012$ \&article $=394>$ (Accessed August 12, 2012).

5. Approved products: Prevnar 13. US Food and Drug Administration. <www.fda.gov/BiologicsBloodVaccines/Vaccines/ApprovedProducts/ ucm201667.htm> (Accessed August 12, 2012).

6. Goldblatt D, Southern J, Andrews N, et al. The immunogenicity of 7 -valent pneumococcal conjugate vaccine versus 23 -valent polysaccharide vaccine in adults aged 50-80 years. Clin Infect Dis 2009;49:1318-25

7. Kelly $\mathrm{H}$ et al. The number needed to vaccinate (NNV) and population extensions of the NNV: Comparison of influenza and pneumococcal vaccine programmes for people aged 65 and over. Vaccine 2004;22:2192-8.
8. Mooney, JD, Weir A, McMenamin J, et al. The impact and effectiveness of pneumococcal vaccination in Scotland for those aged 65 and over during winter 2003/2004. BMC Infect Dis 2008;8:53.

9. Moberley SA, Holden J, Tatham DP, Andrews RM. Vaccines for preventing pneumococcal infection in adults. Cochrane Database Syst Rev 2008;(1):CD00042.

10. Díez-Domingo J, Ridao-López M, Gutiérrez-Gimeno MV, Puig-Barberá J, Lluch-Rodrigo JA, Pastor-Villalba E.

Pharmacoeconomic assessment of implementing a universal PCV-13 vaccination programme in the Valencian public health system (Spain). Vaccine 2011;29:9640-8.

11. Smith KJ, Wateska AR, Nowalk MP, Raymund M, Nuorti JP, Zimmerman RK. Cost-effectiveness of adult vaccination strategies using pneumococcal conjugate vaccine compared with pneumococcal polysaccharide vaccine. JAMA 2012;307:804-12.

12. Centers for Disease Control and Prevention. Use of 13-valent pneumococcal conjugate vaccine and 23-valent pneumococcal polysaccharide vaccine for adults with immunocompromising conditions: Recommendations of the Advisory Committee on Immunization Practices (ACIP). MMWR Morb Mortal Wkly Rep 2012;61:816-9.

13. CDC. Updated recommendations for prevention of invasive pneumococcal disease among adults using the 23 -valent pneumococcal polysaccharide vaccine (PPSV23). MMWR Morb Mortal Wkly Rep 2010;59:1102-6.

14. Talbot TR, Hartert TV, Mitchel E, et al. Asthma as a risk factor for invasive pneumococcal disease. N Engl J Med 2005;35:2082-90.

15. Klemets P, Lyytikäinen $O$, Ruutu P, et al. Risk of invasive pneumococcal infections among working age adults with asthma. Thorax 2010;65:698-702.

16. Juhn YJ, Kita H, Yawn BP, et al. Increased risk of serious pneumococcal disease in patients with Asthma. J Allergy Clin Immunol 2008;122:719-23.

17. Programme de surveillance du pneumocoque, rapport 2011. Institut National de Santé Publique du Québec. <www.inspq.qc.ca/pdf/ publications/1570_ProgSurvPneumocoque_2011.pdf $>$ (Accessed February 8, 2013).

18. An Advisory Committee Statement (ACS). National Advisory Committee on Immunization (NACI). Statement on the use of conjugate pneumococcal vaccine -13 valent in adults

(PNEU-C-13). Can Commun Dis Rep 2013;39(ACS-5):1-52.

19. Kellner JD. Update on the success of the pneumococcal conjugate vaccine. Paediatr Child Health 2011;16:233-6.

20. Kellner JD, Vanderkooi OG, MacDonald J, Church DL, Tyrrell GJ, Scheifele DW. Changing epidemiology of invasive pneumococcal disease in Canada, 1998-2007: Update from the Calgary-Area Streptococcus pneumonia Research (CASPER) study. Clin Infect Dis 2009;49:205-12.

21. CDC. Prevention of pneumococcal disease among infants and children - use of 13-valent pneumococcal conjugate vaccine and 23-valent pneumococcal polysaccharide vaccine: Recommendations of the Advisory Committee on Immunization Practices (ACIP). MMWR Morb Mortal Wkly Rep 2010;59(RR11):1-18. 


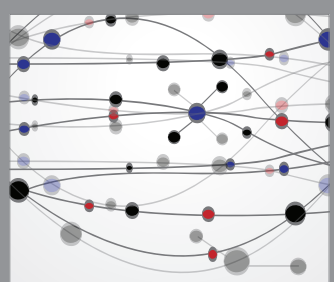

The Scientific World Journal
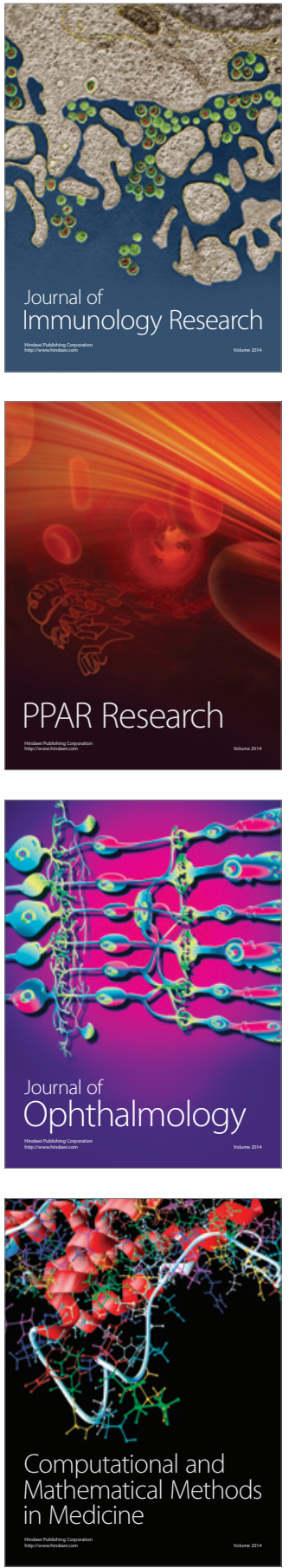

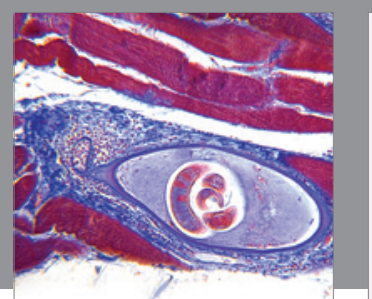

Gastroenterology Research and Practice

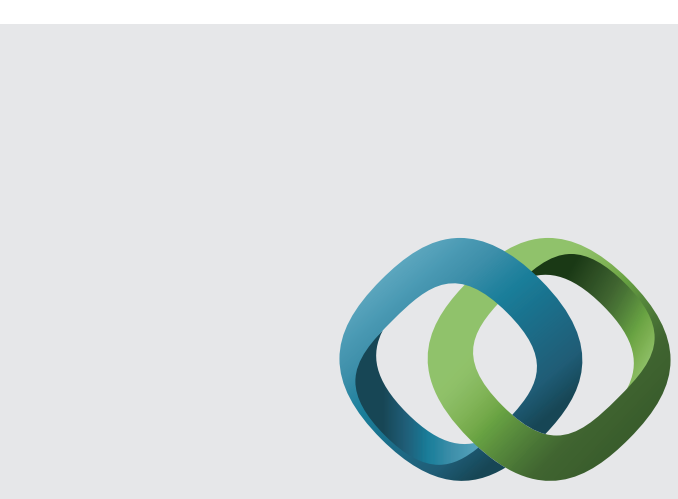

\section{Hindawi}

Submit your manuscripts at

http://www.hindawi.com
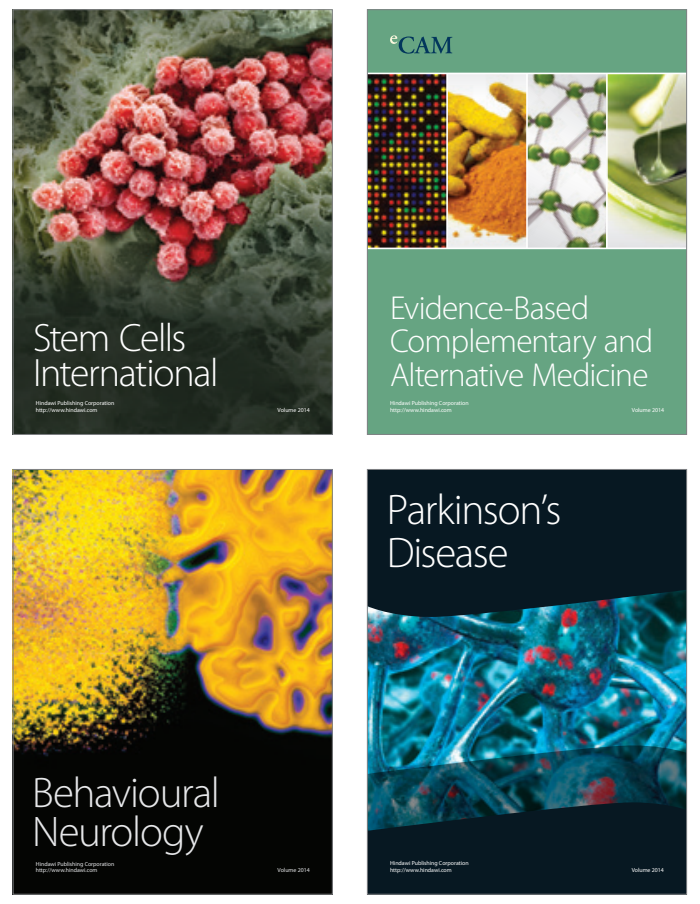
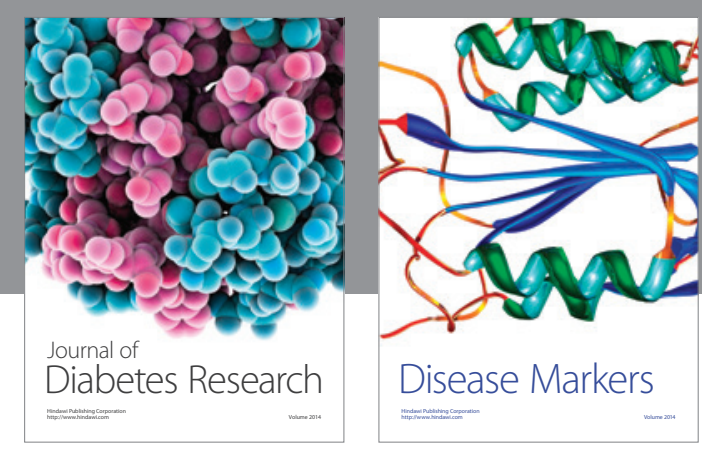

Disease Markers
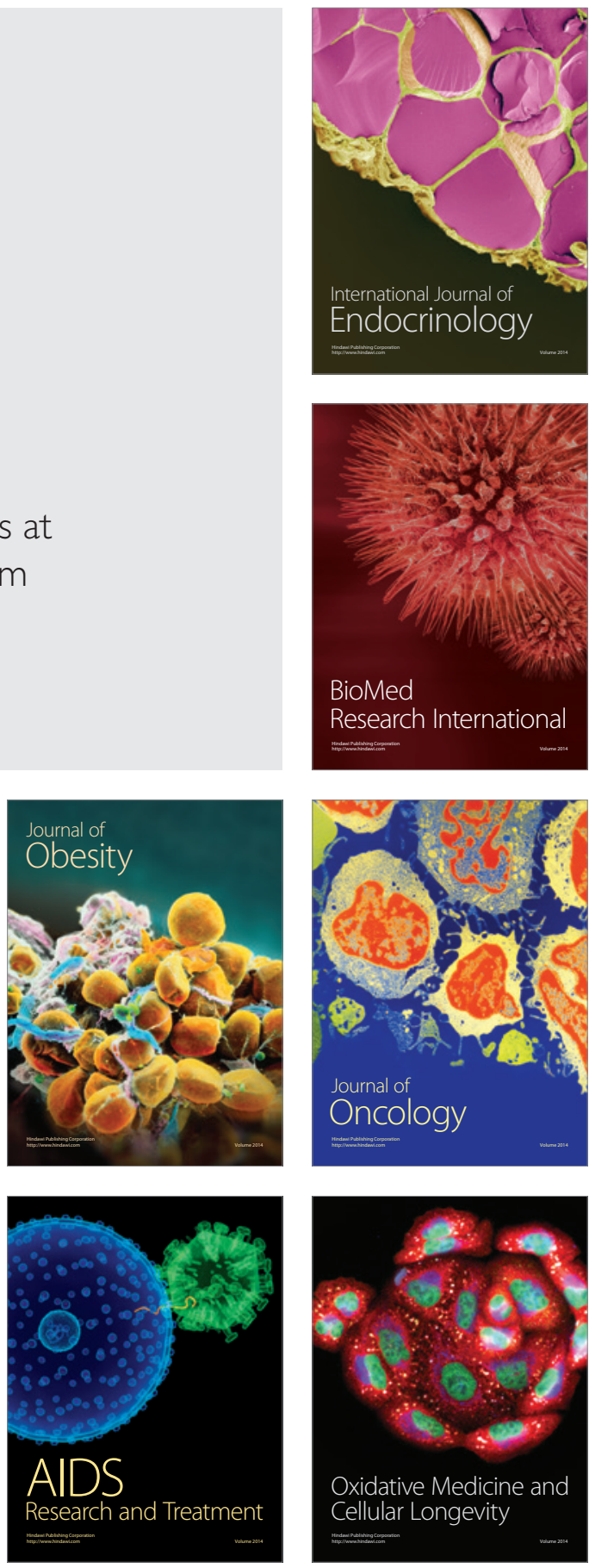